4. Laurmann. J.A. Climatic Change 7.261 - 265 (1985).

5. Ravetz, J. in Science for Public Policy (eds Dowling. M. \& Yared. R.) International Institute for Applied Systems Analysis 27.42 (1 $14 \times 5)$

6. Michacl P. el al. Climatic Change 3. 137-153 (1981)

\section{Misuse of statistics in social sciences}

Sik-Two letters, one from Van Valen', the other from O'Quigley and Baudoin', have warned against the indiscriminate use of null hypothesis testing and the confusion of level of significance with scientific certainty. The situation is worse even than they make it seem, at least in the social sciences.

As Van Valen points out, R.A. Fisher developed the analysis of variance not for hypothesis testing but to aid scientific questioning. Instcad it is used in the social sciences to come to scientifically irrelevant decisions about null hypotheses. My alpha (the level at which I reject the null hypothesis), cautious person that I am, is always one in a million. Yours is one in ten. We both live by the rules. You get a lot of significant results (or almost so, or highly so); I get none. Who is right scientifically?

Guttman ${ }^{3}$ argues that hypothesis testing as used in the social sciences is, strictly speaking, anti-scientific. Science is about the accumulation of information and testing by replication. Hypothesis testing is used to dodge replication and come to immediate decisions. Yet one test of significance leaves indeterminate the probability of the outcome of the next test on a new sample. In other words tests of significance are not cumulative and do not remove the need to replicate. The result is a landscape dotted with isolated studies forming no pattern and making no collective sense. Guttman also points out what is obvious on reflection, that simultaneous $F$ tests on rows, columns, interactions and so on, routine in the social sciences and built into packages such as SPSS, encounter the same problem that simultaneous tests do; they are not independent. The same error flutter that makes one contrast improbable can affect another. The logic of hypothesis testing for any other than the one-way analysis of variance is flawed.

The Neyman-Pearson statistical tools are framed in terms of a loss function: the money or resources that a decision will cost. They are designed to minimize losses in gambling, farming, industry and war. It was gamblers who first demanded probability theory and agriculturists who adopted inferential statistics. Their common problem was the need to makc decisions under risk. Social scientists. faced with difficult experimental problems, took up hypothesis testing faute de mieux to make progress rapidly and to lend their endeavours the appearance if not the reality of scientific respectability. It is in fact irrelevant to science which is concerned with making sense, not conserving resources.
The bankruptcy of programmes of research based on the crutch of the $F$ test is revealed by the choice of the null hypothesis. It is almost always that a correlation or a mean difference is zero. If knowledge were accumulating the incumbent hypothesis would hardly ever be that of no correlation or no effect. Yet this is what is tested routinely, as if all that had gone before counted for nought. It is correct to be dubious about the claims of little old ladies to tell by taste how cups of tea were poured, milk first or second. We can calculate probabilities and find them out. just as we can detect fudging, by Mendel and by Burt. The hypothesis of no effect is the correct one for improbable claims, of psychokinesis or water divining, for example. But it is not correct when we have a body of knowledge to draw on and a theory designed to predict not just that something will happen but what and how much.

The fault does not lie with statisticians Their job is to tell us how to do statistics, not science. It is scientists who have to work out how to do science. By misunderstanding the scientific use of statistical tools social scientists have created a situation every bit as bad as Guttman says it is Puttering along, making the same old mistakes, will in the end bring the whole enterprise into disrepute.

Department of Psychology,

University of Western Australia,

Nedlands W.A. 6009, Australia

1. Van Vaklen. L. Nanure 314, 230) (19k5) (1977): Appl. Sictuistic al Models Datu Anulysis I (in the press)

\section{No to new photosynthetically} active radiation units

SIR-In response to R.A. Lewin (Nature 316, 582; 1985), who proposes a new unit to measure photosynthetically active radiation, certain misconceptions should be dispelled. The photosynthetically active photon flux density (PPFD) is the quantity of photons incident on a unit area per unit time. It is not, as claimed, light intensity which is the luminous flux emitted by a point source into a unit solid angle (SI unit, cd), nor is it uniquely PAR (photosynthetically active radiation) which is commonly used for the radiant power $(400-700 \mathrm{~nm})$ incident on a unit area per unit time (SI unit. $\mathrm{Wm}^{-2}$ ).

Communication between ecophysiologists has been greatly aided by the adoption of SI units. A particular advance has been the use of PPFD (units: $\mu \mathrm{mol} \mathrm{m}^{-2} \mathrm{~s}^{-1}$ ). This unit is consistent with those of $\mathrm{O}_{2}, \mathrm{CO}$ and $\mathrm{H}_{2} \mathrm{O}$ fluxes, greatly simplifying the calculation of derived parameters such as quantum efficiency of efficiency of water use.

There are limitations to the use of PPFD. Density is confusing for a flux through a unit area rather than volume The term is biased to land plants being limited to the photosynthetically active wavelengths $(400-700 \mathrm{~nm})$. However. the 'alb', the new unit proposed by Lewin. solves none of these problems and only adds to the confusion.

Lewin also complains that PPFD requires the use of the Greek letter. $\mu$. which is awkward to type. Awkward as it may be, modern scientific word-processing packages can easily solve this problem. In any case. SI derived units are composed of base units, thus the 'alb' would be mol m' $\mathrm{s}^{-1}$, and avoidance of negative exponents. abhorred by Lewin, would require the use of the ' $\mu \mathrm{alb}$ '. Does the author object similarly to $\mu \mathrm{g}$ and $\mu \mathrm{m}$ ? Plants, especially algae, differ in their absorption spectra, but unless sensors can be designed to fit each individual plant, there is no practical solution to this problem, and the alb provides no advance. If Einstein's first name be abbreviated to alb, let it be for an advance in science and not for a unit which solves no problems and adds to the confusion of light measurements.

C.L. Beadle

CSIRO, Hobart

H. BOLHAR-NORDENKAMPF

University of Vienna

J.-E. HALLGREN

Swedish University of Agricultural Sci., Umeå

M.B. JONES

Trinity College, Dublin

University of Essex

S.P. LONG*

*Address for correspondence: S.P. Long, Department of Biology, University of Essex, Colchester CO4 3SQ, UK.

StR--To contradict Lewin's recent letter suggesting the alb as a radiation unit, instead of "einstein'. I consider that there is no confusion in the physics community about the use of the einstein. The ubiquitous ratio (velocity)/(velocity of light) $=\mathrm{v} / \mathrm{c}$ is commonly known as $\beta$. and is otherwise not named. The authority for this statement is (1) your nearest friendly physics text. (2) excellent physicists. (3) one not-so-excellent physicist (L.X.F.).

Einstein's contributions to physics are incomparably wide and basic. So many units would be justifiably named after him than none is.

\section{Department of Physics}

Leonard X. Finegold

and Atmospheric Science.

Drexel University.

Philadelphia.

Pennsylvania 1904, USA

\section{Scientific Correspondence}

Scientific Correspondence is intended to provide a forum in which readers may raise points of a rather technical character which are not provoked by articles or letters previously published (where the Matters Arising section remains appropriate). 